\title{
The Progress of Man*
}

$\mathrm{T}^{\mathrm{n}}$ $\mathrm{HE}$ necessity of considering a number of controversial topics can be avoided by omitting to define the term progress, but it is generally agreed that progress, like degeneration, involves change, and while progress leads upward from a starting point, degeneration takes a downward course.

The material needs and aims of man claim first attention of a technologist. They may be grouped in a relatively small number of 'types of satisfactions'. Each of these has acquired in course of time a greater and greater variety, and a more and more involved technique of means of fulfilment, comprised in part of methods and natural materials, in part of artefacts, in varied combinations. We do not perhaps estimate the level of a culture by the nature and multiplicity of its aims; but it must be recognized that progress has depended on proliferation of aims, as much as on the multiplication of means. It might gratify our self-esteem if we could think that man's progress was determined by persistence in his aims; but this is only true of civilized communities, in which directional investigation has transformed the quest of means by inflation of the aims.

Much importance must be attached to man's attitude towards the possibility of progress in a general sense; and it is necessary to emphasize the fact that the idea is not inherent in the human mind. It is a conception of future possibilities, developed from the study of past actualities, and adopted as a framework of modern thought. We are justified in assuming that, to the early discoverers and inventors, the general idea of progress was lacking. It may be justifiably asked, however, whether the lack of a general idea of progress must be fatal to progressive steps in human culture. Since man had made great material advances long before the idea was formulated, it is clear that these were not due to perseverance in an aim that he had set before himself. As in so many spheres of human thought, theory followed practice.

That the natural environment plays an influential part in the early stages of cultural progress is obvious enough. Only in proportion as the natural environment is swamped by the artificial, does man acquire a freedom which enables him to overcome the limitations of his habitat. His success in this direction has at various periods resulted in a cultural momentum,

* Substance of the presidential address entitled "Concerning Human Progress" delivered by Dr. H. S. Harrison before the Royal Anthropological Institute on June 30 . which has taken him far from his starting point. In spite of the fact that the achievement of a high material equipment, and even a domineering empire, has often been succeeded by a crash, there has always been a continuity in many cultural elements, upon which further progress could be based. The cultivation of plants, the domestication of animals, the working of iron, and much else, once learnt, have never been forgotten, and there has, therefore, been a fluctuating continuity in human progress. But although there has been this continuity in important elements of culture, there are many instances in which its absence is conspicuous. There have been numerous false starts, numerous blind ends in human progress.

Observation and applied discoveries arise out of the opportunism that takes advantage of the accident which reveals a possibility. Here we must postulate a limited amount of foresight, leading to an adaptation or combination of known processes and methods to produce a new result. But it is the habit of the discoverer and inventor to proceed along any line that gives immediate results, and he is unable to choose the route of greatest promise. The human mind has seemed to wander without guidance--though usually in the end arriving somewhere-amongst the many possibilities of discovery and invention, striking into paths that ended blindly, returning to an old starting point, creating spurious needs and multiplying superfluities, and, in general, moving forwards, backwards, or sideways in or out of control, without knowing what its destination might turn out to be.

If material progress has been of this nature, it is clear that social progress, whether in the higher or the lower grades of culture, has had no better guidance. The customs and laws of human com. munities are the objective, though immaterial, products of the human mind, reacting through the ages to the stresses and strains of the environment, natural and artificial. They are comparable with the more substantial products of discovery and invention. In both, there has been an evolution, which has trespassed far beyond the biological necessities, and we are entitled to inquire whether the mind of man has been moulded in response to, and in correlation with, the exuberance of his egoistic culture. It is often said that "human nature doesn't change". Does it, or doesn't it ? If it does not, can it?

The conception of the nature of human progress, here set forth, makes no allowance for an expansion 
of man's inherited capacity for taking pains successfully. The assumption has been made that ancient man and modern man are on the average essentially alike in potential brain-power. It might seem that the remarkable control over natural materials and forces, with the resulting creation of miracles of mechanism, is evidence that modern civilized man must be born with faculties of a higher order than those of the early representatives of Homo sapiens. But most of our 'miracles' are the products of the last few hundred years, and the more spectacular have emerged within the present century. In the time of Queen Elizabeth, the civilization of Europe could boast of little that was much beyond the material achievements of the old civilizations of the Near East. It can scarcely be asserted that the brain of a modern Englishman is of better quality than that of an Elizabethan. Since early times, there have been no processes of artificial selection, no eugenic measures, that can have aided in fostering types with better brains. If anything, the methods of civilization often appear to have the opposite result.

The earliest and first type of Homo sapiens to appear on the spade of the archæologist is Aurignacian man, and the proposition may be argued that his physical likeness to ourselves was not accompanied by any innate and fundamental dissimilarity in brain-power. In the evolution of his material culture, man still relies upon the faculties that served his prehistoric ancestors, and if we feel less confident in making the same assumption as regards his innate moral and intellectual qualities, we need only look upon the stage of large parts of Europe and Africa to-day to realize that the experience and wisdom of millennia have failed to establish the brotherhood of man on a reciprocal basis.

If modern man, as compared with ancient man, has undergone a change of heart and mind, we are entitled to inquire by what biological compulsion this has come about. Since the human mind has determined human progress, we must consider whether those factors which are believed by some biologists to have been active in organic evolution in general can have been working on the human brain during the time that has elapsed since Homo sapiens first and finally became the man of modern type.

Of the various factors which have been suggested as responsible for the production of the highest type of tailless ape. natural selection, orthogenesis and use-inheritance alone concern us, as it is directional factors we seek. Yet of these it can be shown that, however much modern man may owe to natural selection for his neanthropic characters, since the directions in which it may have acted as regards man's intellectual and moral qualities are those determined by his arti- ficial social conditions, the selection can scarcely be regarded as natural. We may admit that intracommunal selection, even in civilized societies, may foster the development of some qualities at the expense of others ; but it is not evident that these qualities are such as can play a part in piloting man's progress along successful lines.

In like manner, if the increase in the size of the brain of mammals were due to an inexplicable momentum, which is imperfectly explained as orthogenesis-an inner urge towards a predetermined end-we cannot assume that the process has led, or will lead, to the production of human minds capable of distinguishing the sidetracks of moral and social progress from the highways. We cannot credit orthogenesis with the power of directing the social organism to a predetermined and desirable end.

Lastly, the factor which, if it could be shown to have been effective, would explain much of the past, and would open up a prospect for the future, namely, use-inheritance, is so strongly repudiated by most biologists that it can only have a speculative value. This is unfortunate, as an easy way to explain the origin of the modern type of man would be by acceptance of the view that both brain and hand were guided to the climax of their neanthropic powers by the summation of inherited ability, increasing through the generations. But if we accept the biological repudiation of this theory, it cannot be applied to man. In any event, we must be prepared to admit that in size and general structure the brain of man appears to have been at a standstill since early neanthropic times.

By way of provisional conclusion, it would seem that the progress of man of the species Homo sapiens cannot be regarded as resulting from a correlated and progressive change of heart and mind. What he was, he is, and what he is, he will be. As an opportunist, born and bred, he will go on building and re-building an environment for himself, the specifications for which are but little in advance of the construction. He knows what he is doing to-day, but to-morrow is out of sight. The mind of man has little sense of direction, and if it may be said to have an ultimate aim, that aim is too obscure for formulation. In the course of ages, man has coerced many of the forces and products of Nature to his will, but this has been a simple task compared with that upon which he is now more and more insistently engaged-the task of reconciling the fundamental weakness of his mind, and especially his power of foresight, with the social and material complexities in which he has involved himself. His hope is in himself, and not in any speculative prospect of a mental transmutation. 